\title{
Educational Inequality and Professional Motivation of a Future Teacher
}

\author{
Mikhail S. Nazarov \\ Far Eastern Federal University \\ Oksana O. Martynenko \\ Far Eastern Federal University \\ Sergey A. Alekseev \\ Far Eastern Federal University \\ Elena V. Soboleva \\ Far Eastern Federal University
}

\begin{abstract}
The professional motivation and interest of the teacher in the students' educational results are the key resources that allow educational institutions to minimize the existing inequality of educational opportunities for members of different social groups. On this point, one of the important issues of professional training of future teachers is the formation of motivation for their professional activity regarded as a factor that ensures the equality of educational opportunities for students from different social groups. Based on the results of empirical studies of different years, the article analyzes the changes that occurred in the professional motivation of students after the Ussuriysk State Pedagogical Institute joined the Far Eastern Federal University (FEFU) in 2011 as the School of Education. The use of the same measuring instruments made it possible to conduct a comparative analysis of the professional motivation of students in different periods.
\end{abstract}

Keywords: educational inequality, professional motivation, educational results, higher pedagogical education

\section{INTRODUCTION}

Contemporary social science is based on the notion of the institutional nature of social inequality and it considers all its various forms and manifestations to be a special kind of metrics that makes it possible to analyze social stratification in all its structural complexity. The same can be made for educational inequality, which, on the one hand, is one of these dimensions, and on the other hand, allows us to consider education a social institution through which this inequality is reproduced.

Today, a certain amount (Osipov \& Matveeva, 2015) of theoretical and empirical research on educational inequality has been accumulated. This educational inequality is generated by the socioeconomic context of the educational process and the cultural capital that is possessed by different families. However, 
such scientific researches are still relevant as the emergence of new types of social risks poses new types of tasks for society. These tasks are mainly of a preventive nature and focus not so much on compensating for existing negative consequences as on analyzing and predicting possible and probabilistic ones.

Therefore, the focus of the research should shift towards the analysis of those conditions under which differentiated instruction becomes redundant (Gorshkov, 2014) and turns from a factor ensuring the personal development into its opposite. Such position makes scientific research of practical nature and, thereby, allows us to focus on the analysis of risks that appear as a result of certain decisions in the field of educational management and show themselves in the form of undesirable side effects. Excluding it, the control over the management of educational inequality is lost. As a result, from the factor contributing to the integration processes in society, differentiated instruction increases social stratification and becomes one of the sources of social problems.

The analysis of educational inequality in Russia, happening under the influence of socioeconomic inequality of students' families, shows that the transition of students from the middle school is crucial for ensuring social justice: among those 9th grade students, who moved to 10 th grade, about $80 \%$ will later go to Universities. Among students who left middle school to opt for vocational education, only $35 \%$ will study in University. It is noted that this earliest branching point is the most significant (Bessundov, Kurakin $\&$ Malik, 2017) for shaping the life trajectory of teenagers brought up in families with low socioeconomic status.

The implementation of the educational process in the remote format will only reinforce this trend. Dukhanina (2020) notes that, as shown by studies conducted by the All-Russian Popular Front (ONF), students' readiness for distance learning is estimated at an average of 2.46 points out of five. However, families of different socioeconomic status will also have different opportunities to solve the difficulties arouse within the family during the educational process in the online format. These opportunities are not only of financial and economic nature. Researches show that (Shpakovskaya, 2015) cultural capital plays an important role. Parents whose cultural capital is assessed as high (unlike parents who do not have it) tend to consider education a joint activity with teachers. For these families, the model "parents - students - teachers" is often a daily practice, and in the new conditions it will not lose its main quality - the involvement of parents in the educational process - even after moving to online.

Therefore, in the context of distance learning, parents with higher level of cultural capital will better organize extracurricular activities for children, control attendance in an online class (according to a metaanalysis by J. Hattie (Borisenko, 2018) tend, the magnitude of the impact of these factors is highly estimated and is in the range of $0.51-0.57)$. That is why students from such families will have an advantage over students with different socioeconomic and cultural opportunities. As a result, the educational inequality increases that further reduce the career chances for students from less socially privileged families.

The shift of general education to a distance learning showed that educational processes are not ready to be immersed into online format. According to the research of ONF, about $80 \%$ of teachers faced problems while switching to distance learning. The list of these difficulties includes technical problems in schools, lack of experience working online, and lack of necessary methodological support for the organization of the educational process in distance format. In general, according to ONF, the readiness of schools and teachers is estimated at an average of 2.78 points out of five.

The immersion of general education into distance learning makes it possible to take a fresh look at such characteristic as teacher motivation. Teaching online is challenging for teachers, as the process itself requires taking a critical look at the educational process and being prepared to develop their teaching skills. Teacher motivation becomes crucial in conditions when teaching becomes as transparent as possible for parents, including those who want to evaluate the quality of the educational process. Reorienting teachers towards new forms of work and expanding their professional horizons will be particularly important for students from socially disadvantaged groups, in whose education teachers and schools play a key role (Kapuza et al., 2017).

The scientific literature reveals a significant influence of teacher motivation on the educational results of students (Kalyar, Ahmad \& Kalyar, 2018). The motivation of the teacher, and as a result, his interest in the educational results of the student are the key resources which allows educational organizations 
(including distance learning, in case if families have required technical means) to ensure equal educational opportunities for representatives of different social groups within the same classroom, one lesson.

On this point, one of the important issues of professional training of future teachers is the formation of motivation for their professional activity regarded as a factor that ensures the equality of educational opportunities for students from different social groups.

\section{PURPOSE AND OBJECTIVES OF THE STUDY}

The aim of the study is to trace the dynamics in professional motivation among students of the Far Eastern Federal University (FEFU) School of Education, studying "Pedagogical Education" and to identify deficits in the professional training of students.

\section{LITERATURE REVIEW}

Today, a certain amount (Osipov \& Matveeva, 2015) of theoretical and empirical research on educational inequality has been accumulated. This educational inequality is generated by the socioeconomic context of the educational process and the cultural capital that is possessed by different families.

The analysis of educational inequality in Russia (Bessundov, Kurakin \& Malik, 2017), happening under the influence of socioeconomic inequality of students' families, shows that the transition of students from the middle school is crucial for ensuring social justice: among those 9th grade students, who moved to 10th grade, about $80 \%$ will later go to Universities. Among students who left middle school to opt for vocational education, only $35 \%$ will study in University. It is noted that this earliest branching point is the most significant for shaping the life trajectory of teenagers brought up in families with low socioeconomic status.

The scientific literature reveals a significant influence of teacher motivation on the educational results of students (Kalyar, Ahmad \& Kalyar, 2018). The motivation of the teacher, and as a result, his interest in the educational results of the student are the key resources which allows educational organizations (including distance learning, in case if families have required technical means) to ensure equal educational opportunities for representatives of different social groups within the same classroom, one lesson.

\section{METHODOLOGICAL GROUNDS}

The empirical basis of the research is based on data collected in 2010 and 2019. The choice of research dates is not accidental: in 2011, the Ussuriysk State Pedagogical Institute (USPI) joined Far Eastern Federal University as the School of Education. It allowed us to narrow the empirical research framework and focus on changes that occurred in the professional motivation among students of different years. The usage of same measuring tools makes it possible to indicate these changes.

The study was based on the hypothesis of positive changes in professional motivation and satisfaction of the students of FEFU School of Education with the profession of a teacher in comparison with students of USPI. The confirmation of this hypothesis would make it possible to talk about the effectiveness of managerial decisions aimed at implementing the FEFU Development Program for 2010 - 2019 in terms of attracting applicants with a high score at the Unified State Exam, winners of Olympiads from the Far Eastern Federal District, other regions of Russia and foreign students" to educational program "Education and Pedagogical Sciences.

The second hypothesis was based on the assumption of the differentiation of students of the FEFU School of Education according to the criterion "training deficits".

To determine the state of professional motivation of students, the indicator "professional motivation of future teachers" was used (the method of Zamfir (2000) in the modification of Rean (2000)). Since the motivation of the teacher is substantively related to the satisfaction with teaching profession, according to the method of Rean (2000), the indicator "satisfaction with the chosen profession of a teacher" was counted. The results of the United State Exam and students professional deficits were also taken into consideration. 
A wide range of statistical methods was used to test these hypotheses: analysis of one-dimensional and two-dimensional (contingency tables) frequency distributions, calculation of a measure of central tendency, one-factor analysis of variance, etc. The calculations were performed using the SPSS statistical analysis package.

\section{RESEARCH RESULTS}

The method of assessing the motivation for professional activity is based on the analysis of the correlations among three forms of: intrinsic motivation (IM), extrinsic positive motivation (EPM) and extrinsic negative motivation (ENM). The best (optimal) correlations among three forms of motivation include following types: (1) IM> EPM $>$ ENM or (2) IM = EPM $>$ ENM.

In the compared studies for graduate students, different types of correlations among forms of professional motivation were recorded. In 2010, it was the sub-optimal type $((\mathrm{IM}) 3.5<(\mathrm{EPM}) 3.6>(\mathrm{ENM}) 3.1))$, while in 2019 the first optimal model prevailed (IM) $3.7>(\mathrm{EPM}) 3.3>(\mathrm{ENO}) 2.2$.

The same could be observed among the first-year students of different years: in the 2010 study a suboptimal type of correlation among forms of professional motivation was recorded ((IM) $3.3<(\mathrm{EPM}) 3.4>$ (ENM)3.0)) and in the 2019 it was the first optimal type: (IM)3.4>(EPM)2.7> (ENM)1.8.

The measured level of satisfaction with the profession of a teacher showed that the average value of the first-year students in 2010 was 2.8 points. For the first-year students in 2019, this indicator was 3.5 points. A one-factor analysis of variance showed that differences in satisfaction rates among first-year students in 2010 and 2019 were statistically significant (significance level $p<0.05$ ).

An analysis of this indicator among graduate students of different years showed a similar dynamic: in 2010 , it was 2.6 and 3.3 in 2019. Differences in the level of satisfaction were also statistically significant.

The proportion of students with the level of satisfaction above the average (3.6 points and above) has changed. Among first-year students of 2019, the percentage of those whose satisfaction level was above the average was $53.3 \%$ compared to $19.4 \%$ in 2010 . In 2019 , the percentage of fifth-year students with satisfaction level more than 3.6 points was $45.6 \%$, while in 2010 only $15.7 \%$ of the students' were satisfied with their chosen profession.

Therefore, a comparative analysis of the results of two studies conducted in 2010 and 2019 showed significant changes in two indicators: "motivation for professional activity" and "satisfaction with the profession of a teacher".

1. Comparing students on such indicator as "motivation for professional activity", students of the FEFU School of Education of the first and graduate years (2019) tend to be better than students of the corresponding courses of USPI (2010). For students in the research conducted in 2019, such motives as satisfaction with the teaching process, results of work, and possibility of selfrealization were more valuable to them than salary and promotion opportunities. For students of 2011, the opposite situation was recorded.

2. The indicator "satisfaction with the profession of a teacher" also showed positive changes. The proportion of the first-year students who showed a higher than average satisfaction level increased: $53.3 \%$ of the first-year students in 2019 compared to $19.4 \%$ in 2010 ; for graduate students, this indicator rose from $15.7 \%$ in 2010 to $45.6 \%$ in 2019.

3. The results of analysis showed that among the students of FEFU School of Education who had a low satisfaction level, 7,1\% of them selected the motive for enrollment in School "the profession of a teacher is taught well at the School of Education". The score of such indicator as the Unified State Exam was 192 points for the sum of three exams. Nevertheless, for this group of students, the first optimal type of correlation among forms of professional motivation was recorded.

4. With an increase in the level of satisfaction (in the range from 2.6 to 4 points), the proportion of those $(33.0 \%)$ who selected the motive "the profession of a teacher is taught well at the School of Education" also increased. The total score of the Unified State Exam, which for this 
group amounted to 195 points for the sum of three exams, is also growing. This group has the first optimal type of correlation among forms of professional motivation.

5. Statistically significant differences in the Unified State Exam scores were recorded among the group with low satisfaction and the group of first-year students with a satisfaction score of more than 4 points. The average score of the United State Exam for this group of students reached 204 points. A comparative analysis using the Mann-Whitney U-test showed the statistical significance of these differences $(p=0.043)$. Moreover, in this group there were a high proportion of students $(61.5 \%)$ who noted the motive "the profession of a teacher is taught well at the School of Education". This group has the first optimal type of correlation among forms of professional motivation.

Therefore, the hypothesis of positive changes in professional motivation and satisfaction with the profession of a teacher of students of the FEFU School of Education in 2019 compared with students of the USPI in 2010 is proved empirically. It is possible to talk about the effectiveness of managerial decisions aimed at attracting high-scoring applicants with high motivation for future professional activities for the direction "Education and Pedagogical Sciences". The motivation of the teacher, and therefore his interest in the educational results of the student, his willingness to put into practice the whole variety of educational content, forms and teaching methods, taking into account the individual and social capabilities of the student, will reduce the influence of the socioeconomic status of the family on the academic success of students and create conditions for self-realization.

The basis for testing the second hypothesis on the differentiation of students of the FEFU School of Education by the criterion "deficits of professional training" was formed by the answers of graduate students to the question "evaluate what knowledge, skills and abilities you lacked during teaching practice". To obtain a more contrasting picture and understand that students were differently ready for pedagogical activity, the satisfaction indicator with the profession of a teacher was used. As a result, it became possible to break the identified deficits into two groups.

The first group included deficits, according to which the difference between the group with a low level of satisfaction and the group whose satisfaction was rated at 4 points and above was in the range from 0 to 5.5 percentage points. These included: "skills to work with students with behavioral problems", "knowing the requirements of the federal state educational standard", "methods of individual teaching (for children with educational problems)", "teaching methods for students with special health needs". These problems are common for all graduate students of the FEFU School of Education.

The second group included those deficits for which the difference between the groups began with 11 percentage points. These are: "the ability to organize the work in the class and to control the behavior of students", "the methodology of teaching talented students", "knowledge in the main subject area (areas)", "mastery of modern methods of teaching subject", "skills of interaction with families of students", " computer and information technology skills for teacher work."

Except "skills of interaction with students' families," in other cases, deficits are more evident in students with a low level of satisfaction (in the range from 1 to 2.5 points). As for the "skills of interacting with students' families," this discrepancy can be explained as follows. An additional analysis showed that $54.5 \%$ of students from the group with low satisfaction noted that this knowledge was not useful for them in practice. This is due to the fact that during the practice these students were less likely to interact with their parents. As for the students with high level of satisfaction (more than 4 points), the percentage of respondents that did not require knowledge in this area was $28 \%$.

Therefore, the data presented support the formulated hypothesis on the differentiation of students according to the criterion of "training deficits".

\section{DISCUSSIONS}

The analysis showed that the current FEFU policy aimed at enlisting school graduates who are aware of their educational and career paths yields positive results. However, it becomes clear that studying in one general educational organization, two hypothetical students with an optimal motivational system, but 
different level of satisfaction with the chosen profession of a teacher, will differently interact with parents, organize lessons, control students behavior, teach students with special educational needs and demonstrate proficiency in using modern approaches in teaching their subject.

In the context of the inequality, it means the following: a student with a higher level of satisfaction, using his pedagogical skills, will strive to remove the difference in educational opportunities between students of different socioeconomic status. Regarding the other case, there is a risk of an increase in social inequality. Such situation makes it possible to consider education as a social institution through which this inequality is reproduced. However, in order to minimize this inequality and exclude its socially dangerous forms, what model of professional training for students studying "Education and Pedagogical Sciences" will be optimal?

\section{CONCLUSION}

It should be said that the implementation of the model of research education in the professional training of future teachers would reduce these risks to a minimum. The basis of such model should be the special focus of the educational process of the FEFU School of Education on the formation of research competence among students studying "Education and pedagogical sciences." A student who has mastered the required research process is ready to use them in teaching. The involvement of students into the research activities will contribute to the intellectual development of students and increase the chances of a career in the knowledge economy for students from less socially privileged families. Based on the research potential of the Federal University, the School of Education stands realistic chances to implement its plan.

\section{REFERENCES}

Bessudnov, A., Kurakin, D., \& Malik, V. (2017). The Myth about Universal Higher Education: Russia in the International Context. Voprosy Obrazovaniya, 3, 83-109.

Borisenko, N.A. (2018). "Barometers" of Influence, or Factors Which Have the Greatest Impact on Learning. A Review of John C. Hattie (2009) Visible Learning: A Synthesis of Over 800 MetaAnalyses Relating to Achievement. Voprosy Obrazovaniya, 1, 257-265.

Dukhanina, L. (2020, Spring). Teachers faced problems of distance learning. News of education. Vogazeta.ru. Retrieved from https://vogazeta.ru/articles/2020/4/7/analitycs/12378uchitelya_stolknulis_s_problemami_distantsionnogo_obucheniya

Gorshkov, M.K. (2014). Social inequalities as an object of sociological analysis. Semeinaya Psikhologiya i Semeinaya Terapiya, (7), 20-31.

Kapuza, A.V., Kersha, Y.D., Zaharov, A.B., \& Havenson T.E. (2017). Educational Attainment and Social Inequality in Russia. Voprosy Obrazovaniya, (4), 10-35.

Kalyar, M., Ahmad, B., \& Kalyar, H. (2018). Does Teacher Motivation Lead to Student Motivation? The Mediating Role of Teaching Behavior. Voprosy Obrazovaniya, (3), 91-119.

Osipov, A.M., \& Matveeva, A.N. (2015). Institutional barriers and education accessibility mechanisms: Conception and regional dynamics. Sotsiologicheskie Issledovaniya, (7), 37-48.

Shpakovskaya, L.L. (2015). The Educational Expectations of Parents: A Mechanism That Reproduces Social Inequality. Zhurnal Issledovaniy Sotsialnoy Politiki, 13(2), 211-224.

Stolyarenko, L.D. (2000). Pedagogical Psychology. Rostov na Donu: Feniks. 